\title{
Norske pasienter med tykktarmskreft kommer for sent i gang med tilleggsbehandling
}

\begin{abstract}
BAKGRUNN For pasienter med tykktarmskreft som ifølge nasjonale retningslinjer skal ha tilleggsbehandling med kjemoterapi, skal denne igangsettes innen 4-6 uker etter det kirurgiske inngrepet. Vi ønsket å undersøke om retningslinjene ble fulgt. Vi ønsket også å undersøke om hvorvidt type kirurgisk behandling (åpen eller laparoskopisk) hadde betydning for tid til oppstart av tilleggsbehandling.
\end{abstract}

MATERIALE OG METODE Materialet består av 1132 pasienter som var operert for tykktarmskreft i perioden 2008-13 og som fikk tilleggsbehandling med kjemoterapi. Kirurgisk behandling og tilleggsbehandling med kjemoterapi er definert ved diagnose- og prosedyrekoder fra Norsk pasientregister for perioden 2008-13.

RESULTATER Det tok gjennomsnittlig 44,7 dager etter det kirurgiske inngrepet før pasientene var i gang med tilleggsbehandling med kjemoterapi. Hos $49 \%$ av pasientene kom ikke tilleggsbehandlingen i gang innen seksukersfristen. Pasienter operert laparoskopisk hadde kortere liggetid (6,5 dager versus 10,7 dager) og færre komplikasjoner (7,6 \% versus 16,4\%) enn pasienter som hadde fått åpen operasjon, likevel kom de ikke i gang med tilleggsbehandlingen tilsvarende tidligere.

FORTOLKNING Det bør gjøres kvalitetsforbedrende tiltak som sikrer at retningslinjene blir fulgt og at pasientene kommer raskere i gang med nødvendig tilleggsbehandling. For dem som behandles laparoskopisk, bør det være enkelt å hente ut gevinsten av kortere liggetid og færre komplikasjoner med raskere oppstart av tilleggsbehandling.

Det har eksistert nasjonale faglige anbefalinger for behandling av tykktarms- og endetarmskreft i Norge siden tidlig i 1990-årene. Pasienter med tykktarmskreft med høy risiko for tilbakefall skal etter gjeldende nasjonale retningslinjer ha tilleggsbehandling med kjemoterapi (1). Slik behandling gis vanligvis over seks måneder hos dem som er under 75 år og skal, ifølge retningslinjene, igangsettes innen 4-6 uker (28-42 dager) etter kirurgi.

Det optimale tidspunkt for oppstart av tilleggsbehandling med kjemoterapi etter kirurgi for tykktarmskreft er ikke identifisert i randomiserte kliniske studier. Det er likevel internasjonal klinisk enighet om at behandlingen bør starte innen 4-8 uker etter operasjonen og at det ikke er hensiktsmessig å gi behandling etter tre måneder, siden hensikten er å ramme eventuelle sirkulerende kreftceller (2). Selv om de nasjonale retningslinjene på dette området har lavt evidensnivå (nivå D), er det ingen grunn til at hvert helseforetak skal ha sin egen praksis. I så fall bør dette begrunnes i hvert enkelt tilfelle. En metaanalyse fra 2011 indikerer at den relative overlevelsen reduseres med $14 \%$ for hver 4. uke tilleggsbehandlingen utsettes (3). En analyse fra det danske kolorektalkreftregisteret viser redusert totaloverlevelse hvis man starter kjemoterapi mer enn 55 dager etter kirurgi (4).

Vi ønsket å undersøke om de nasjonale retningslinjene knyttet til tid for oppstart med tilleggsbehandling ble fulgt opp ved norske helseforetak, dessuten om det var forskjeller i tid til oppstart av tilleggsbehandling etter forskjellig type kirurgi.

\section{Materiale og metode}

Denne studien er en del av forskningsprosjektet Analyser av pasientforløp, som har konsesjon fra Datatilsynet og dispensasjon fra taushetsplikten fra den regionale etiske forskningskomiteen. Konsesjonen gir tilgang til personentydige data fra Norsk pasientregister med opplysninger om pasienter behandlet ved norske sykehus $\mathrm{i}$ perioden 2008-13.

Krypterte pasientløpenumre gjør det mulig å beskrive pasientforløp som involverer flere sykehus og går over flere år. I tillegg til utvalgte pasientopplysninger, som for eksempel bosted og kjønn, gir konsesjonen tilgang til enkelte administrative og medisinske data - som eksempelvis institusjoner, behandlingsnivå, diagnosekoder (ICD-10) og prosedyrekoder (Norsk klassifikasjon av medisinske prosedyrer (NCMP) og nordisk klassifikasjon av kirurgiske inngrep (NCSP)).

\section{Studiepopulasjon}

Utvalget i denne studien består av pasienter som er operert for tykktarmskreft i perioden 2008-13, definert ved diagnosekoden for tykktarmskreft (C18) og ved kirurgiske prosedyrekoder som indikerer fjerning av deler av eller hele tykktarmen.

\author{
Frank Olsen \\ Bård Uleberg \\ Senter for klinisk dokumentasjon og evaluering \\ (SKDE) \\ Helse Nord RHF
}

Bjarne Koster Jacobsen

Senter for klinisk dokumentasjon og evaluering (SKDE)

Helse Nord RHF

og

Institutt for samfunnsmedisin

Universitetet i Tromsø - Norges arktiske

universitet

\section{Lise Balteskard}

lise.balteskard@skde.no

Senter for klinisk dokumentasjon og evaluering (SKDE)

Helse Nord RHF

Engelsk oversettelse på www.tidsskriftet.no

\section{HOVEDBUDSKAP}

Halvparten av pasientene som skal ha tilleggsbehandling med kjemoterapi for tykktarmskreft kommer senere i gang enn anbefalt i nasjonale retningslinjer

Pasienter operert laparoskopisk har kortere liggetid og færre komplikasjoner, men kommer likevel ikke tilsvarende raskere i gang med tilleggsbehandlingen enn dem som blir operert med åpen kirurgi 
Pasienter med kreftdiagnose og kirurgi i samme opphold, 2008-13:

12356 pasienter

Ekskludert: Pasienter med fjernmetastase innen 90 dager etter kirurgi: 1979 pasienter

Pasienter med kurativ intensjon:

10377 pasienter

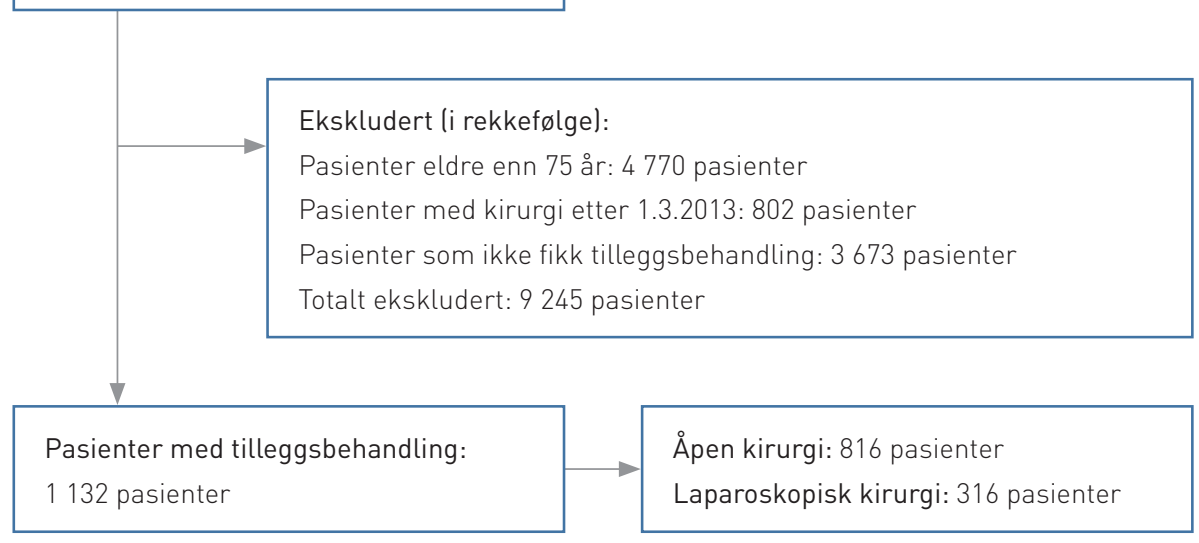

Figur 1 Pasientutvalg fra Norsk pasientregister

Åpen kirurgi er definert ved prosedyrekodene JFB20, JFB30, JFB33, JFB40, JFB43, JFB46，JFB50，JFB60，JFB63，JFB96， JFH00, JFH10 og JFH96. Laparoskopisk kirurgi er definert ved prosedyrekodene JFB21, JFB31, JFB34, JFB41, JFB44, JFB47, JFB51, JFB61, JFB64, JFB97, JFH01 og JFH11.

Innleggelsesdato for kirurgioppholdet pluss to dager ble benyttet som operasjonsdato, da vi ikke hadde tilgang til prosedyredato.

Pasienter som hadde fått utført relevant kirurgi på tykktarmen og i samme opphold hadde fått diagnosen «forstadium til kreft» (D01) eller «usikker kreft» (D37) ble inkludert dersom de i løpet av 120 dager etter estimert operasjonsdato fikk en sikker kreftdiagnose (C18) eller i løpet av 200 dager fikk utført etterundersøkelse etter behandling for ondartet svulst (Z08) (12 356 pasienter).

Pasienter som ble operert for tykktarmskreft og som ikke var kodet for fjernmetastaser (C77.0, C77.1, C77.3, C78* eller C79*) innen 90 dager etter estimert operasjonsdato, ble antatt å ha begrenset sykdom og motta behandling med kurativ intensjon og således være tilgjengelige for tilleggsbehandling (10 377 pasienter).

For å ha lang nok oppfølgingsperiode til å kunne vurdere om kjemoterapi i seks måneder var gitt etter primær kirurgisk behand- ling, ble kun pasienter med estimert operasjonsdato tidligere enn ti måneder før datasettets slutt (dvs. innleggelsesdato før 1.3. 2013) inkludert i pasientutvalget. Pasienter over 75 år er normalt ikke aktuelle for tilleggsbehandling ved tykktarmskreft og ble ekskludert (fig 1). Pasienter som manglet diagnosekoden $\mathrm{C} 18$ i perioden mens tilleggsbehandling med kjemoterapi pågikk eller hadde koder for fjernmetastaser (hoved- eller bidiagnoser) $\mathrm{i}$ denne perioden eller som ikke fikk tilleggsbehandling, ble også ekskludert. Totalt ble 9245 pasienter ekskludert.

Kjemoterapi ble identifisert med diagnosekode Z51.1*, takst H05a og/eller prosedyrekodene WBOC05, WBOC08 eller WBOC20. Pasienter ble definert som mottakere av tilleggsbehandling med kjemoterapi dersom denne startet innen 90 dager etter estimert operasjonsdato og ett av to behandlingsmønstre ble gjenfunnet (1 132 pasienter):

- Inntil 12 kurer mottatt i løpet av 210 dager, med et intervall på minimum to uker mellom hver kur (5-fluorouracil og kalsiumfolinat kombinert med oksaliplatin)

- Inntil åtte kurer mottatt i løpet av 210 dager med oppstart hver tredje uke (kapecitabin/oksaliplatin)

Pasienter med komplikasjoner eller reopera- sjoner ble identifisert med enten diagnosekode for komplikasjoner (T81.0-81.9, T88.8, Y83.2) eller en prosedyrekode for reoperasjon $\left(\mathrm{JW}^{*}\right)$ i samme opphold som kirurgien ble utført eller innen 30 dager etter estimert operasjonsdato. Totalt ble 158 pasienter identifisert med komplikasjoner.

\section{Statistisk metode}

Analysene er utført med statistikkprogrammet SAS (SAS Institute, Cary, N.C.). Her analyseres hele populasjonen, ikke bare et utvalg. Det angis derfor ikke p-verdier for forskjeller mellom forskjellige grupper og kategorier. For å analysere sammenhengen mellom tid til oppstart av tilleggsbehandling og liggetid og alder er det utført regresjonsanalyser.

\section{Resultater}

I alt 1132 pasienter (fig 1) fikk tilleggsbehandling med kjemoterapi. $52 \%$ var kvinner. Gjennomsnittsalderen var 62,7 år, og det var liten forskjell i gjennomsnittsalder mellom menn og kvinner. Det var heller ikke stor forskjell i gjennomsnittsalder for pasienter operert laparoskopisk og pasienter operert åpent. Samlet hadde $14 \%$ av pasientene komplikasjoner eller reoperasjoner. Det er kun små forskjeller mellom menn og kvinner når det gjaldt andel med komplikasjoner. Komplikasjonsandelen var mer enn dobbelt så høy for dem som var operert åpent som for dem som var operert laparoskopisk (tab 1).

Gjennomsnittlig liggetid var 9,5 dager, og den var forholdsvis lik for menn og kvinner. Det var betydelig lengre liggetid for pasienter som var operert med åpen teknikk enn for pasienter som var operert laparoskopisk (tab 1).

Det var ikke betydelige forskjeller når det gjaldt alder ved operasjonstidspunktet, liggetid og komplikasjoner helseforetakene imellom, men det var forskjeller mellom helseforetakene når det gjaldt tid til oppstart av tilleggsbehandling med kjemoterapi (fig 2).

Det tok gjennomsnittlig 44,7 dager (median 42 dager) etter det kirurgiske inngrepet før pasientene var i gang med tilleggsbehandling. For $49 \%$ av pasientene kom man ikke i gang med tilleggsbehandlingen innen siste frist i de nasjonale retningslinjene (42 dager), og for $14,5 \%$ av pasientene startet tilleggsbehandlingen senere enn 55 dager.

De som var operert laparoskopisk, kom 0,8 dager raskere i gang med tilleggsbehandlingen enn de som var operert åpent (henholdsvis 44,1 dager og 44,9 dager). Pasienter med komplikasjoner/reoperasjoner startet tilleggsbehandling med kjemoterapi gjennomsnittlig 5,0 dager senere enn pasienter som ikke hadde hatt komplikasjoner/reoperasjoner $\mathrm{i}$ forløpet (henholdsvis 49,0 dager og 44,0 dager). 

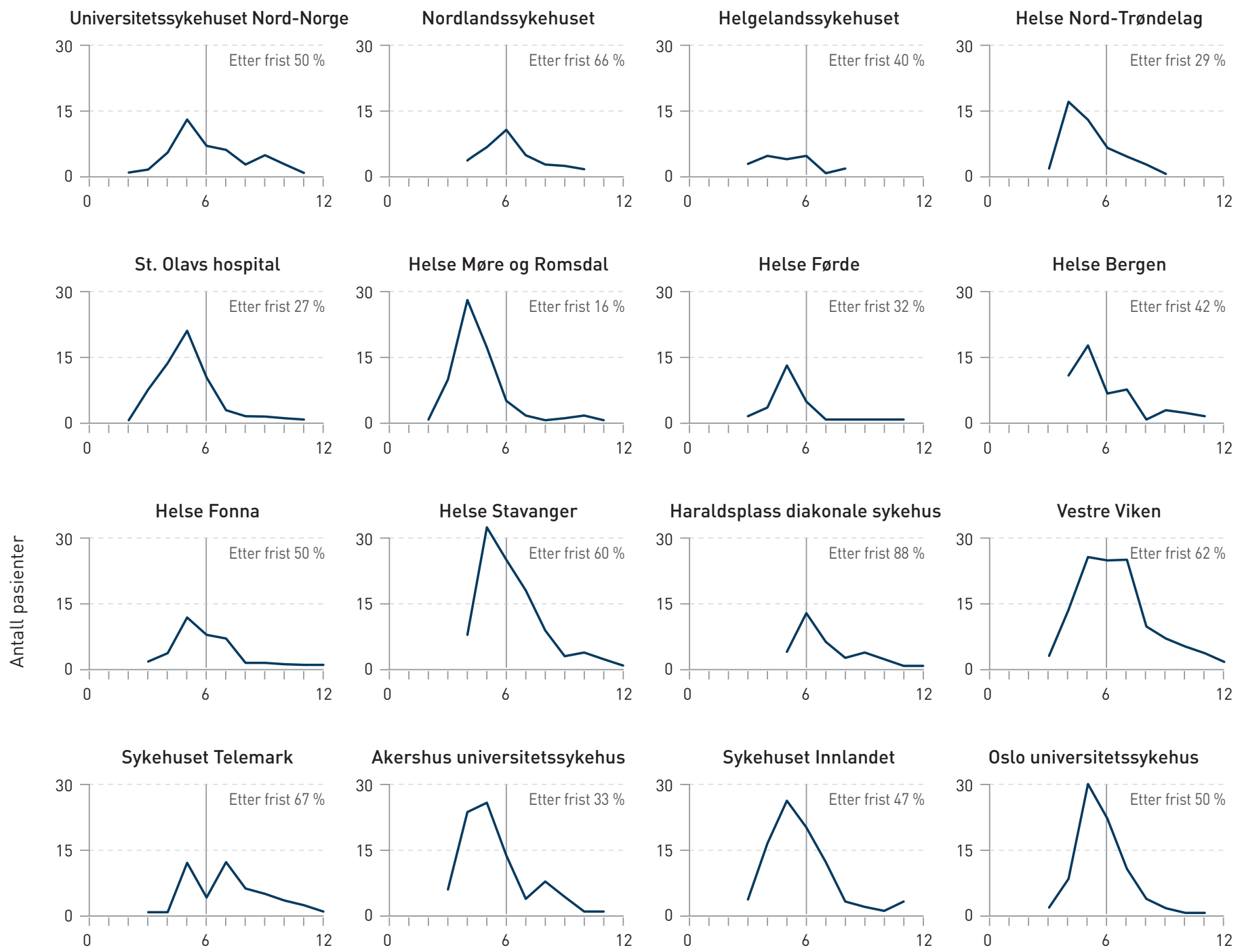

Sykehuset Østfold

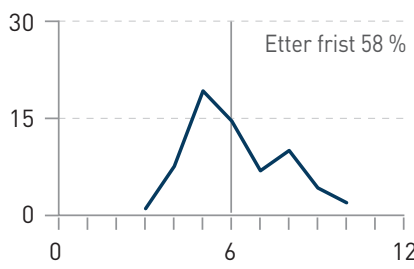

Sørlandet sykehus

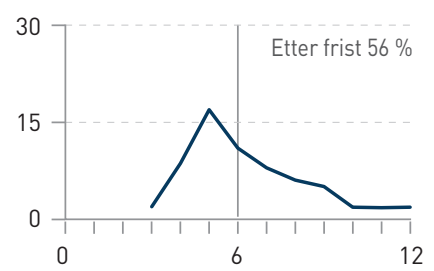

Sykehuset i Vestfold

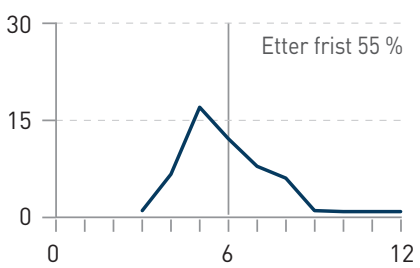

Diakonhjemmet

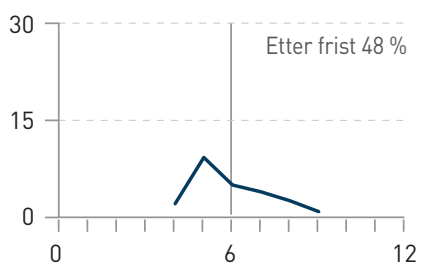

Uker til oppstart med adjuvant kjemoterapi

Finnmarkssykehuset HF vises ikke pga. lavt antall

Figur 2 Antall pasienter med tid til oppstart med tilleggsbehandling med kjemoterapi ved tykktarmskreft fordelt på helseforetak i perioden 2008-13. Vertikal linje markerer seks uker (42 dager), siste anbefalte frist for oppstart i henhold til nasjonale retningslinjer

Det var en positiv sammenheng mellom tid til oppstart av tilleggsbehandling med kjemoterapi og liggetid og alder. Ett ekstra liggedøgn førte til at pasienten kom i gang med tilleggsbehandlingen om lag en halv dag senere. Dette resultatet var det samme uavhengig av om pasienten var operert laparoskopisk eller åpent. Eldre pasienter kom senere i gang med til- leggsbehandling. Gjennomsnittlig økte tiden til tilleggsbehandling med 0,13 dager når alderen økte med ett år. Også dette var uavhengig av type kirurgi. Tid til oppstart med tilleggsbehandling, justert for alder, var 44,2 dager og 44,9 dager for pasienter behandlet med henholdsvis laparoskopi og åpen kirurgi. Justering for alder har altså kun marginal betydning.

\section{Diskusjon}

I Norge er det anbefalt at man skal komme i gang med tilleggsbehandling med kjemoterapi i løpet av 28-42 dager etter det kirurgiske inngrepet. Denne studien viser at det gjennomsnittlig tar 44,7 dager (medianverdi 42 dager) dager fra estimert dato for kirurgi til tilleggsbehandlingen starter. For $49 \%$ av 
Tabell 1 Pasienter som har fått tilleggsbehandling med kjemoterapi ved tykktarmskreft. Antall pasienter, alder, andel med komplikasjoner, liggetid og tid til oppstart tilleggsbehandling, etter kirurgitype og kjønn, Norge 2008-13. Antall (\%), gjennomsnitt (SD) eller andel (antall)

\begin{tabular}{lrrrrrrr} 
& \multicolumn{2}{c}{ Totalt } & \multicolumn{2}{c}{ Menn } & \multicolumn{2}{c}{ Kvinner } \\
& 1132 & $(100 \%)$ & 541 & $(48 \%)$ & 591 & $(52 \%)$ \\
Antall (\%) & 316 & $(28 \%)$ & 156 & $(14 \%)$ & 160 & $(14 \%)$ \\
\hline Laparoskopi & 816 & $(72 \%)$ & 385 & $(34 \%)$ & 431 & $(38 \%)$ \\
Åpen kirurgi & 62,7 & $(9,5)$ & 62,5 & $(9,4)$ & 62,9 & $(9,6)$ \\
Alder lår), gjennomsnitt (SD) & 61,8 & $(9,9)$ & 62,1 & $(9,5)$ & 61,6 & $(10,3)$ \\
Laparoskopi & 63,0 & $(9,3)$ & 62,7 & $(9,4)$ & 63,3 & $(9,3)$ \\
Åpen kirurgi & 14,0 & $(158)$ & 14,6 & $(79)$ & 13,4 & $(79)$ \\
Komplikasjoner, prosentandel lantall) & 7,6 & $(24)$ & 9,6 & $(15)$ & 5,6 & $(9)$ \\
\hline Laparoskopi & 16,4 & $(134)$ & 16,6 & $(64)$ & 16,2 & $(70)$ \\
Åpen kirurgi & 9,5 & $(6,8)$ & 9,6 & $(7,2)$ & 9,4 & $(6,5)$ \\
Liggetid, gjennomsnitt (SD) & 6,5 & $(4,2)$ & 6,6 & $(5,3)$ & 6,5 & $(2,9)$ \\
\hline Laparoskopi & 10,7 & $(7,3)$ & 10,8 & $(7,5)$ & 10,6 & $(7,0)$ \\
Åpen kirurgi & 44,7 & $(11,9)$ & 44,7 & $(11,4)$ & 44,7 & $(12,3)$ \\
Dager til tilleggsbehandling, gjennomsnitt (SD) & 44,1 & $(11,0)$ & 45,2 & $(10,5)$ & 43,1 & $(11,5)$ \\
\hline Laparoskopi & 44,9 & $(12,2)$ & 44,5 & $(11,8)$ & 45,3 & $(12,6)$ \\
Åpen kirurgi & & & & & & \\
\hline
\end{tabular}

pasientene ble fristen som er satt i retningslinjene overskredet. Det er derfor ikke bare noen få pasienter som er kraftig forsinket mange kommer sent i gang.

Pasienter operert med laparoskopisk teknikk har kortere liggetid og færre komplikasjoner, men kommer likevel ikke vesentlig raskere i gang med tilleggsbehandling med kjemoterapi enn pasienter som er operert med åpen teknikk.

Faktorer som forsinker oppstarten av kjemoterapi er postoperative komplikasjoner eller annen sykdom hos pasienten som må utredes eller behandles først. Dette kan ikke alene forklare at halvparten kommer i gang etter fristen eller at pasienter med kort liggetid og ingen postoperative komplikasjoner kommer for sent i gang. Denne forsinkelsen kan mest sannsynlig forklares av fravær av gode pasientforløp og henvisningsrutiner. Kvalitetsregisteret for tykk- og endetarmskreft har kvalitetsindikatorer med vekt på kirurgisk teknikk (5). Kvalitetsforbedrende tiltak bør i fremtiden inkludere også den onkologiske behandlingen.

Den danske kolorektalkreftgruppen har publisert at det gjennomsnittlig tok 43 dager til oppstart av tilleggsbehandling med kjemoterapi for pasienter uten anastomoselekkasje og 59 dager for dem med anastomoselekkasje (4). Tilsvarende tidsbruk i Norge var 44 dager for pasienter uten og 49 dager for pasienter med komplikasjoner og/eller reoperasjoner. Den danske studien viste at mortaliteten var høyere hos dem som kom i gang med tilleggsbehandling med kjemoterapi først etter 55 dager (4). I vår analyse kommer $14,5 \%$ av pasientene i gang med tilleggsbehandling så sent.

Det er i denne sammenheng interessant å merke seg at den relative overlevelsen opp til fem år etter diagnosedato har vært stort sett uendret fra perioden 2008-10 til perioden 2011-13 (5).

Det er viktig å registrere og kvalitetssikre den onkologiske behandlingen i kvalitetsregistret på samme måte som man kvalitetssikrer den kirurgiske behandlingen. Den økte oppmerksomheten som pakkeforløpene for kreft medfører vil forhåpentligvis ha effekt på det totale pasientforløpet, ikke bare frem til første behandling. Økt kunnskap om pasientforløp kombinert med mer data fra kvalitetsregisteret vil gi gode forutsetninger for kvalitetsforbedrende tiltak for denne pasientgruppen. De samlede svakhetene i pasientforløpene må identifiseres og endringer iverksettes. Dette bør ivaretas i en kontinuerlig prosess.

\section{Metodiske betraktninger}

Det er tidligere vist at kvaliteten på koding av tykktarms- og endetarmskreft i Norsk pasientregister er tilfredsstillende (6). Erfaringsvis kan det likevel antas at kodingen av komplikasjoner ikke er optimal. Slutninger bør trekkes med forsiktighet. I Nasjonalt kvalitetsregister for tykk- og endetarmskreft mangler det opplysninger om komplikasjoner i $3 \%$ av tilfellene (5).

Til kvalitetsregisteret rapporteres det komplikasjoner under det enkelte sykehusopphold, mens i denne studien er alle komplikasjoner innen 30 dager inkludert. Til tross for noe ulik definisjon er det godt samsvar mellom komplikasjonsandelen fra Norsk pasientregister og kvalitetsregisteret for tykk- og endetarmskreft ( $14 \%$ og $17 \%$ ). Identifisering av reoperasjoner gjennom prosedyrekoden $\mathrm{JW}^{*}$ gir ikke komplett oversikt, da denne koden erfaringsvis ikke alltid brukes ved reoperasjoner. Den er likevel vurdert som den beste identifiseringsmetoden. Alternativer løsninger innebærer risiko for å inkludere prosedyrer som ikke er reoperasjoner.

Pasienter med høy risiko for komplikasjoner og reoperasjoner, for eksempel de som lider av fedme og akutte tilstander i buken, vil av mange kirurger selekteres til åpen kirurgi. Dette kan forklare at det i denne studien påvises flere komplikasjoner og reoperasjoner hos dem som er operert med åpen kirurgi. Annen komorbiditet vil også kunne påvirke valget av type kirurgi. Pasientseleksjonen har imidlertid ikke betydning for vår konklusjon - at kortere liggetid og færre komplikasjoner for pasienter operert laparoskopisk ikke fører til tilsvarende raskere igangsetting av nødvendig tilleggsbehandling.

Mangelen på sikker operasjonsdato i våre data er en mulig feilkilde. Ca. $14 \%$ av pasientene legges inn som øyeblikkelig hjelp og blir sannsynligvis operert i løpet av det første døgnet (5). Resten opereres vanligvis 1-3 dager etter innleggelsen. Et gjennomsnittlig estimat på operasjonsdato to dager etter innleggelse synes derfor rimelig. Konklusjonen - at mange kommer for sent i gang med tilleggsbehandling - er likevel ikke påvirket av om estimert operasjonsdato er noen få dager feil. Tid til tilleggsbehandling vil fremdeles overstige anbefalingen på 28-42 dager for en betydelig andel av pasientene.

Denne analysen favner hele den norske populasjonen av pasienter med tykktarmskreft i perioden 2008-13. Vi har tatt for oss deler av pasientbehandlingen som ikke var registrert i Nasjonalt kvalitetsregister for tykk- og endetarmskreft. Denne studien illustrerer derfor at Norsk pasientregister, til tross for nevnte metodiske utfordringer, er en verdifull datakilde.

Vi takker Trygve Deraas ved Senter for klinisk dokumentasjon og evaluering for verdifulle innspill til manuskriptet. 


\section{Frank Olsen (f. 1969)}

er cand.polit. i samfunnsøkonomi og analytiker. Forfatter har fylt ut ICMJE-skjemaet og oppgir ingen interessekonflikter.

\section{Bård Uleberg (f. 1973)}

er cand.polit. i sosiologi og analytiker.

Forfatter har fylt ut ICMJE-skjemaet og oppgir ingen interessekonflikter.

\section{Bjarne Koster Jacobsen (f. 1956)}

er professor i epidemiologi og medisinsk statistikk og seniorforsker.

Forfatter har fylt ut ICMJE-skjemaet og oppgir ingen interessekonflikter.

\section{Lise Balteskard (f. 1960)}

er onkolog, dr.med. og fagsjef. Hun var sekretær, senere leder for Norsk Gastrointestinal Cancergruppe i perioden 2004-09.

Forfatter har fylt ut ICMJE-skjemaet og oppgir ingen interessekonflikter.

\section{Litteratur}

1. Nasjonalt handlingsprogram med retningslinjer for diagnostikk, behandling og oppfølging av tykkog endetarmskreft. Oslo: Helsedirektoratet, 2013.

2. Hershman D, Hall MJ, Wang $X$ et al. Timing of

adjuvant chemotherapy initiation after surgery for stage III colon cancer. Cancer 2006; 107: 2581-8.

3. Biagi JJ, Raphael MJ, Mackillop WJ et al. Association between time to initiation of adjuvant chemotherapy and survival in colorectal cancer: a systematic review and meta-analysis. JAMA 2011; 305: 2335-42.

4. Krarup PM, Nordholm-Carstensen A, Jørgensen $L N$ et al. Anastomotic leak increases distant recurrence and long-term mortality after curative resection for colonic cancer: a nationwide cohort study. Ann Surg 2014; 259: $930-8$.

5. Nasjonalt kvalitetsregister for tykk- og endetarmskreft. Årsrapport 2008-2014. Tykktarmskreft 1996-2014. Endetarmskreft 2015. Oslo: Norsk gastrointestinal cancergruppe, Kreftregisteret, 2015

6. Bakken IJ, Gystad SO, Christensen 00 et al. Sammenlikning av data fra Norsk pasientregister og Kreftregisteret. Tidsskr Nor Legeforen 2012; 132: 1336-40.

Mottatt 20.6. 2014, første revisjon innsendt 9.4. 2015, godkjent 28.10. 2015. Redaktør: Inge Rasmus Groote. 